\title{
Frailty-associated factors among Brazilian community-dwelling elderly people: longitudinal study
}

\author{
Maycon Sousa Pegorari', Darlene Mara dos Santos Tavares" \\ Universidade Federal do Triângulo Mineiro (UFTM), Uberaba (MG), Brazil
}

'PhD. Physiotherapist and Adjunct Professor, Physiotherapy Course, Universidade Federal do Amapá (UNIFAP), Macapá (AP), Brazil. (D) orcid.org/0000-0003-4015-9895

"PhD. Nurse and Associate Professor, Department of Nursing Education and Community Health Nursing Graduate Program, Universidade Federal do Triângulo Mineiro (UFTM), Uberaba (MG), Brazil.

(D) orcid.org/0000-0001-9565-0476

\section{KEY WORDS (MeSH terms):}

Frail elderly.

Longitudinal studies.

Health services for the aged.

Urban population.

Primary prevention.

\section{AUTHOR KEY WORDS:}

Frailty assessment.

Frailty syndrome.

Frailty phenotype.

\begin{abstract}
BACKGROUND: Frailty among elderly people is associated with negative health outcomes. Through gaining better understanding of this syndrome over different time periods, healthcare actions that take predictive factors into consideration may be facilitated.

OBJECTIVE: To identify factors associated with frailty syndrome among community-dwelling elderly people over a two-year follow-up.

DESIGN AND SETTING: Longitudinal study on elderly people living in Uberaba (MG), Brazil.

METHODS: Elderly individuals were selected through multiple-stage conglomerate sampling from a national database. Participants were interviewed and evaluated in 2014 and again in 2016. Predictors were considered at the baseline, and frailty categories (frail, pre-frail or non-frail) at the follow-up. Frailty was identified based on the Fried criteria. Associations with socioeconomic factors, health status and physical performance were investigated using multinomial logistic regression.

RESULTS: 353 individuals participated in both assessments. The final model showed that age over 80 years was predictive of both pre-frailty and frailty (odds ratio, OR 4.92; 95\% confidence interval, Cl: 1.57-15.38; OR 8.64; $95 \%$ Cl: 2.05-36.35, respectively), while dependency regarding basic activities of daily living (OR 3.66; 95\% Cl: 1.22-11.02) and poor lower-limb physical performance (OR 7.87; 95\% Cl: 1.97-31.39) predicted frailty. A one-unit increased score for advanced activities of daily living decreased the frailty rate by $15 \%$ (OR 0.85; 95\% Cl: 0.74-0.99).

CONCLUSION: Age over 80 years was predictive of pre-frailty and frailty, while dependency in basic activities of daily living and poor physical performance predicted frailty. A one-unit increased score for advanced activities of daily living decreased the frailty rate by $15 \%$.
\end{abstract}

\section{INTRODUCTION}

Frailty among elderly people is considered to be a priority within public health. One reason for this is that presence of this syndrome predicts occurrences of adverse events that threaten the long-term sustainability of healthcare actions and systems. Moreover, frailty presents a negative influence on elderly people's quality of life. ${ }^{1}$

Physical frailty is "a medical syndrome with multiple causes and contributing factors" that is characterized by impairment of "strength, endurance and physiological functions", thus leading to "greater individual vulnerability in developing functional dependency and/or death". ${ }^{2}$ From an operational point of view, the two measurements of frailty that have been most used (with high validity and reliability) are Fried's frailty phenotype and Rockwood and Mitnitski's frailty index. ${ }^{3}$

In a systematic review, frailty was found to be associated with several sociodemographic, physical, biological, lifestyle and psychological factors. ${ }^{4}$ Moreover, some risk factors for frailty were identified, such as advanced age, female gender, black race, lower income, lower educational level, cardiovascular diseases, multimorbidity, functional impairment, poor self-rated health, depressive symptoms, cognitive impairment, obesity, undernutrition, smoking and alcohol use. ${ }^{5}$

In Brazil, however, the available evidence is only recent and there is a lack of longitudinal studies analyzing the factors that determine frailty. ${ }^{6,7}$ In a study on 207 community-dwelling elderly people who were followed up for 12 months, the factors associated with frailty that predicted worsening of frailty status were histories of cancer, urinary incontinence and reduced capacity to perform advanced activities of daily living. ${ }^{6}$ Another one-year investigation conducted among 129 elderly people after hospital discharge did not identify any variables that were predictive of change (improvement or worsening) to frailty condition. ${ }^{7}$ 
Feng et al. ${ }^{5}$ considered that it was essential to determine the factors associated with frailty when developing interventions to prevent or reduce the frailty-associated burden among community-dwelling elderly people.

\section{OBJECTIVE}

Given the low number of studies within the elderly population of Brazil and the need to understand the factors that determine frailty, the aim of this study was to identify frailty-associated factors among community-dwelling elderly people over a two-year follow-up.

\section{METHODS}

\section{Ethics}

This study was approved (protocol no. 493,211, dated December 13, 2013, and protocol no. 573,833, dated March 28, 2014) by the human-research ethics committee of the Federal University of the Triângulo Mineiro (Universidade Federal do Triângulo Mineiro, UFTM).

\section{Study design, participants and sample size}

This was a longitudinal study, conducted among elderly people living in the urban area of Uberaba, state of Minas Gerais (MG), over a two-year follow-up (2014-2016). Uberaba is the main municipality of the area known as the "Triângulo Sul" of Minas Gerais, which is composed of 27 municipalities in the Triângulo Mineiro region of this state. In 2010, the estimated population of Uberaba was 328,272 citizens, its human development index (HDI) was 0.772 and life expectancy was 75.7 years. ${ }^{8}$ According to data from the Brazilian Institute for Geography and Statistics (Instituto Brasileiro de Geografia e Estatística, IBGE), Uberaba had an elderly population (i.e. of age greater than or equal to 60 years) of 37,365 people in 2010 , which represented $12.62 \%$ of the total population. ${ }^{8}$

Population definition was done using a multiple-stage conglomerate sampling process. This process took into consideration the sectors defined by the Brazilian National Household Survey, with information from neighborhoods and streets that was made available by IBGE. Random household selection was conducted to identify elderly people in their homes.

The sample for the present study was composed of individuals who met the following inclusion criteria: (a) they participated at both times (2014 and 2016); (b) they did not present any cognitive deficit, as identified using the translated and validated Brazilian version of the Mini-Mental State Examination (MMSE), with cutoff points defined according to their educational level; ${ }^{9}$ (c) they were able to walk, with or without the use of walking aids (cane, crutches or walkers); and (d) they agreed to participate in the survey through signing a free and informed consent statement. Participants were excluded in the following situations: (a) inability to reach the participant, even after three attempts; (b) moving to another city; (c) occurrence of hospitalization at the time of the visit; and (d) presence of diseases that prevented the assessments. In the 2014 baseline assessment, 710 elderly people were interviewed.

In 2016, attempts were made to reach all the elderly people who had participated in the first stage of the survey $(n=710)$, in their homes. After the eligibility criteria and the losses had been taken into consideration (detailed in Figure 1; other reasons could be insufficient address or incomplete data), 353 elderly people were considered in the present investigation. Thus, these 353 individuals were evaluated both in 2014 and in 2016 .

Because of the possibility of reading and comprehension problems, the interviews with the elderly people were conducted faceto-face in their homes. Therefore, interviewers (who were undergraduate and postgraduate students) were selected and trained regarding ethical issues within research and, additionally, they were accompanied by field supervisors (senior researchers).

\section{Dependent variable}

The presence of frailty syndrome was investigated using the five items that Fried et al. described as components of the frailty phenotype. ${ }^{10}$ These were the following: (1) Presence of non-intentional weight loss, as assessed through the question "In the past year, did you lose $4.5 \mathrm{~kg}$ without intention?"; (2) Muscle strength loss verified based on handgrip strength, using a manual hydraulic dynamometer; the mean value from three measurements was obtained and the cutoff points proposed by Fried et al. ${ }^{10}$ were used; (3) Self-reported exhaustion and/or fatigue, as measured through two questions: "Did you feel that you had to make an effort to take care of your habitual tasks?" and "Were you unable to move forward with your things?"; (4) Presentation of

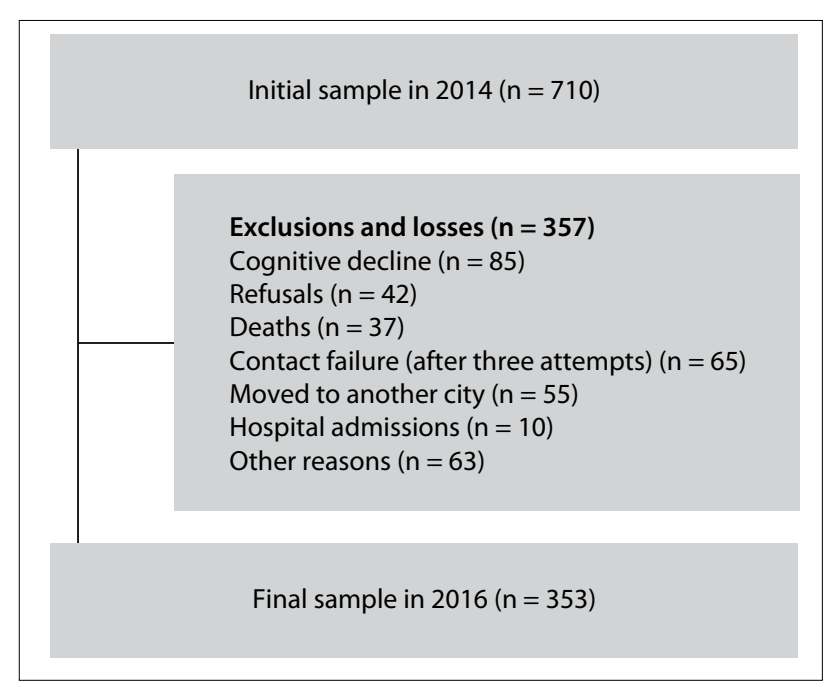

Figure 1. Study sample flow diagram. 
slow walking speed, considering the time (in seconds) that was taken to walk a distance of $4.6 \mathrm{~m}$, with the cutoff points as proposed by Fried et al.; ${ }^{10}$ and (5) Poor physical activity level, as ascertained using the long version of the International Physical Activity Questionnaire (IPAQ). Elderly people presenting three or more of these items were classified as frail; those with one or two of these items were classified as pre-frail; and those with none of these items were considered to be robust or non-frail. ${ }^{10}$ A detailed description of the components can be accessed in previous publications. ${ }^{10-12}$

\section{Exploratory variables}

The following were considered to be exploratory (independent) variables:

1. Socioeconomic characteristics - age range in years (60 to 69,70 to 79 or 80 or over), sex (male or female), marital status (with or without a companion), living arrangements (alone or with company), schooling in years (none, 1 to 4 or 5 or more) and individual monthly income in minimum wages (no income, less than or equal to 1 minimum wage, or 2 or more minimum wages);

2. Clinical health indicators - number of diseases, number of regular medications, health self-perception (very poor, poor, fair, good or very good), hospital admissions in the past 12 months (yes or no) and falls in the past 12 months (yes or no);

3. Functional incapacity - measured using patient-reported outcomes such as the Katz scale ${ }^{13}$ for basic activities of daily living (BADL); the Lawton and Brody scale for instrumental activities of daily living (IADL), ${ }^{14}$ categorized as dependent (total or partial dependency) or independent (without incapacity for BADL and IADL); and 13 questions of a social nature for advanced activities of daily living (AADL), ${ }^{15}$ in which the response alternatives were "never did", "stopped doing" or "still doing", with scoring in the range of 1-3 points, a minimum score of 13 points and a maximum of 39 points;

4. Fear of falling - measured using the Falls Efficacy Scale International - Brazil (FES-I Brazil), which was analyzed as a continuous variable, with scores ranging from 16 to $64,{ }^{16}$ and

5. Physical performance - assessed using the Brazilian version of the Short Physical Performance Battery (SPPB), which was categorized as follows: $0-3$ points, very poor performance; 4-6 points, poor performance; 7-9 points, moderate performance; and 10-12 points, good performance. ${ }^{17}$

\section{Statistical analysis}

Statistical analysis was done using the absolute and percentage frequency distribution for categorical variables and central trend (mean) and dispersion (standard deviation) measurements for quantitative variables. Univariate and multivariate analyses were done using logistic multinomial regression analysis, in order to investigate associations between the exploratory variables and the dependent variable (frailty status). Thus, the exploratory variables (predictors) were obtained from the baseline (2014) and the frailty status (frail, pre-frail or non-frail) was obtained from the follow-up assessment (2016). The variables of interest were chosen in accordance with the criterion established $(\mathrm{P}<0.20)$ and were included in the multivariate regression model. Predictors associated with pre-frailty and frailty were identified using odds ratios, through multinomial logistic regression, considering a significance level of $5 \%(\mathrm{P}<0.05)$ and a $95 \%$ confidence interval (CI). The data were analyzed using the Statistical Package for the Social Sciences (SPSS), version 21.0.

\section{RESULTS}

In 2014, the majority of the 353 elderly people who were interviewed were women, in the age range of 60-69 years, and were living with a companion. Table 1 presents the distribution of the socioeconomic variables according to frailty status at the baseline.

Table 2 presents the univariate analysis on the frailty-associated factors during the follow-up. Predictors were considered at the baseline, and frailty categories (frail, pre-frail or non-frail) in the follow-up assessment.

The variables included in the multivariate model of the multinomial logistic regression are presented in Table 3. Age in the range of 80 years or over was a predictor of both frailty $(\mathrm{OR}=$ 8.64; $95 \%$ CI: $2.05-36.35)$ and pre-frailty $(\mathrm{OR}=4.92$; CI: $1.57-$ 15.38), while dependency in basic activities of daily living ( $\mathrm{OR}=$ 3.66; 95\% CI: 1.22-11.02) and poor physical performance (OR = 7.87; 95\% CI: 1.97-31.39) were predictors of frailty. Additionally, the results indicated that an increase of one point in the score for advanced activities of daily living decreased the rate of occurrence of the condition of frailty among these elderly individuals by $15 \%$ $(\mathrm{OR}=0.85$; 95\% CI: 0.74-0.99) (Table 3).

\section{DISCUSSION}

The present study identified frailty predictors over a two-year follow-up period. These included advanced age, dependency relating to BADL and poor physical performance. On the other hand, ability to perform AADL provided a protective effect.

The results indicated that advanced age ( 80 years or over) was an independent predictor for both pre-frailty and frailty. Other investigations have also found that age was a frailty marker, ${ }^{18-20}$ including two systematic reviews. ${ }^{4,5}$

Age is an important indicator of the association between frailty categories and mortality. ${ }^{21}$ A systematic review indicated that the numbers of pre-frail and frail elderly people become greater at advanced ages, which suggests that frailty is a progressive condition and, hence, that it may appear more frequently among elderly people older than 80 years. ${ }^{5}$ Moreover, Fulop et al..$^{22}$ discussed the existence 
of common but non-identical pathways of frailty and aging; they suggested that the characteristics of frailty syndrome were more accentuated than those of regular ageing. Thus, all individuals older than 70 years would need to be screened for frailty syndrome, in order to improve the management of individuals with this condition. ${ }^{2,23}$
The association of BADL dependency as a frailty predictor seen in the present study is divergent from the findings of other Brazilian studies. ${ }^{6,7}$ Nevertheless, an investigation in Italy, with a 4.4-year follow-up, found that worsening of the condition presented by non-frail individuals was associated with dependency

Table 1. Socioeconomic, clinical and health variable distribution among the elderly people, according to the condition of frailty at the baseline. Uberaba (MG), Brazil, $2014(n=353)$

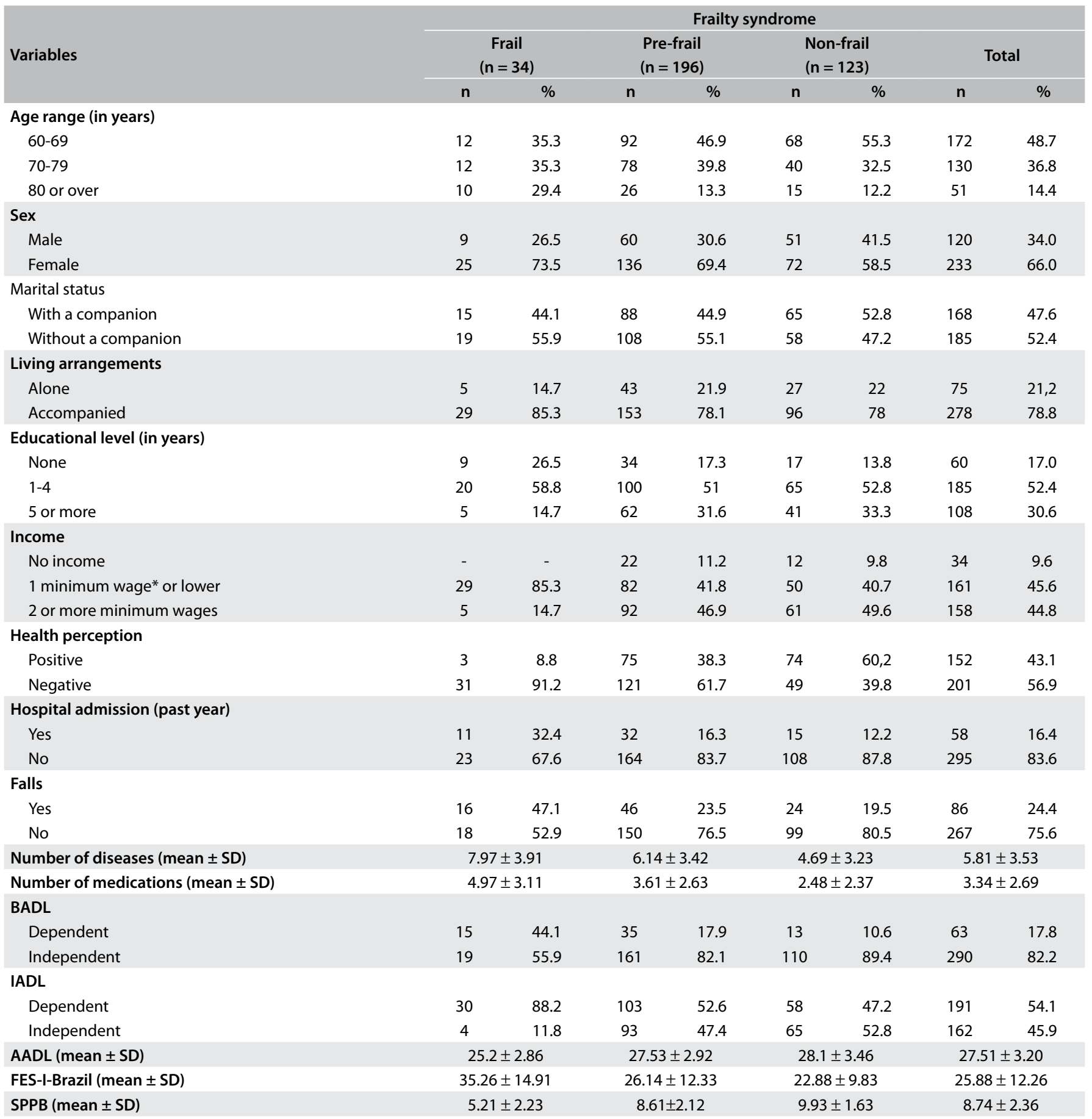

$B A D L=$ basic activities of daily living; $\mid A D L=$ instrumental activities of daily living; $A A D L=$ advanced activities of daily living; FES-I-Brazil = Falls Efficacy Scale International - Brazil; SPPB = Short Physical Performance Battery; SD = standard deviation.

*Minimum wage in Brazil in 2014: R\$ 724.00/month (US\$ 175.50); and in 2016: R\$ 880.00/month (US\$ 213.32). 
in relation to activities of daily living. ${ }^{18}$ Furthermore, according to Fried et al., ${ }^{24}$ functional incapacity may cause difficulty in accessing healthcare services or actions from healthcare professionals, which would lead to increases in unrecognized and unaddressed healthcare needs. ${ }^{24}$ Thus, implementation of monitoring actions and control over functional incapacity factors are strategies not

Table 2. Socioeconomic, clinical and health variables associated with the condition of frailty, using univariate analysis. Uberaba (MG), Brazil, 2014-2016 ( $\mathrm{n}=353)$

\begin{tabular}{|c|c|c|c|c|c|c|}
\hline \multirow{3}{*}{ Variables } & \multicolumn{6}{|c|}{ Frailty syndrome } \\
\hline & \multicolumn{3}{|c|}{ Pre-frail } & \multicolumn{3}{|c|}{ Frail } \\
\hline & OR & $95 \% \mathrm{Cl}$ & $\mathbf{P}$ & OR & $95 \% \mathrm{Cl}$ & $\mathbf{P}$ \\
\hline \multicolumn{7}{|l|}{ Age range (in years) } \\
\hline $60-69$ & & 1 & & & 1 & \\
\hline $70-79$ & 1.68 & $1.01-2.78$ & 0.045 & 2.17 & $0.97-4.85$ & 0.058 \\
\hline 80 or over & 6.47 & $2.19-19.13$ & 0.001 & 16.10 & $4.64-55.84$ & $<0.001$ \\
\hline \multicolumn{7}{|l|}{ Sex } \\
\hline Male & & 1 & & & 1 & \\
\hline Female & 0.86 & $0.53-1.42$ & 0.567 & 0.98 & $0.47-2.04$ & 0.952 \\
\hline \multicolumn{7}{|l|}{ Marital status } \\
\hline With a companion & & 1 & & & 1 & \\
\hline Without a companion & 0.88 & $0.55-1.41$ & 0.601 & 1.01 & $0.50-2.01$ & 0.980 \\
\hline \multicolumn{7}{|l|}{ Living arrangements } \\
\hline Alone & 0.92 & $0.52-1.63$ & 0.788 & 0.98 & $0.43-2.27$ & 0.984 \\
\hline Accompanied & & 1 & & & 1 & \\
\hline \multicolumn{7}{|l|}{ Educational level (in years) } \\
\hline None & 2.04 & $0.94-4.41$ & 0.071 & 2.71 & $0.99-7.44$ & 0.052 \\
\hline $1-4$ & 1.22 & $0.72-2.05$ & 0.456 & 0.92 & $0.41-2.04$ & 0.837 \\
\hline 5 or more & & 1 & & & 1 & \\
\hline \multicolumn{7}{|l|}{ Income } \\
\hline No income & 0.86 & $0.39-1.89$ & 0.714 & 0.44 & $0.09-2.16$ & 0.315 \\
\hline 1 minimum wage or lower & 1.22 & $0.74-2.01$ & 0.429 & 1.71 & $0.83-3.52$ & 0.147 \\
\hline 2 or more minimum wages & & 1 & & & 1 & \\
\hline \multicolumn{7}{|l|}{ Health perception } \\
\hline Positive & & 1 & & & 1 & \\
\hline Negative & 1.38 & $0.86-2.21$ & 0.177 & 2.58 & $1.23-5.44$ & 0.012 \\
\hline \multicolumn{7}{|l|}{ Hospital admission (past year) } \\
\hline Yes & 1.25 & $0.65-2.43$ & 0.503 & 1.74 & $0.72-4.23$ & 0.221 \\
\hline No & & 1 & & & 1 & \\
\hline \multicolumn{7}{|l|}{ Falls } \\
\hline Yes & 1.71 & $0.94-3.11$ & 0.080 & 3.25 & $1.49-7.08$ & 0.003 \\
\hline No & & 1 & & & 1 & \\
\hline Number of diseases (mean $\pm S D$ ) & 1.05 & $0.98-1.13$ & 0.133 & 1.15 & $1.05-1.27$ & 0.004 \\
\hline Number of medications (mean $\pm \mathrm{SD}$ ) & 1.05 & $0.96-1.15$ & 0.271 & 1.19 & $1.06-1.36$ & 0.004 \\
\hline \multicolumn{7}{|l|}{ BADL } \\
\hline Dependent & 1.62 & $0.79-3.28$ & 0.183 & 5.19 & $2.24-12.07$ & $<0.001$ \\
\hline Independent & & 1 & & & 1 & \\
\hline \multicolumn{7}{|l|}{ IADL } \\
\hline Dependent & 2.26 & $1.39-3.64$ & 0.001 & 4.05 & $1.91-8.56$ & $<0.001$ \\
\hline Independent & & 1 & & & 1 & \\
\hline AADL & 0.94 & $0.87-1.01$ & 0.111 & 0.78 & $0.71-0.89$ & $<0.001$ \\
\hline FES-I-Brazil (mean \pm SD) & 1.01 & $0.99-1.03$ & 0.246 & 1.04 & $1.01-1.07$ & 0.003 \\
\hline \multicolumn{7}{|l|}{ Physical performance (SPPB) } \\
\hline Very poor & 3.82 & $0.44-33.52$ & 0.226 & 56.87 & $6.18-523.79$ & $<0.001$ \\
\hline Poor & 2.80 & $1.07-7.31$ & 0.035 & 23.02 & $7.03-75.33$ & $<0.001$ \\
\hline Moderate & 1.78 & $1.07-2.94$ & 0.025 & 3.07 & $1.18-8.01$ & 0.022 \\
\hline Good & & 1 & & & 1 & \\
\hline
\end{tabular}

$\mathrm{OR}=$ odds ratio; $95 \% \mathrm{Cl}=95 \%$ confidence interval; $\mathrm{P}<0.20 ; 1$ = reference category - non-frail group; $\mathrm{BADL}=$ basic activities of daily living; $\mid \mathrm{ADL}=$ instrumental activities of daily living; AADL = advanced activities of daily living; FES-I-Brazil = Falls Efficacy Scale International - Brazil; SPPB = Short Physical Performance Battery. 
only for maintaining functional capacity among elderly people, ${ }^{25-26}$ but also for prevention of consequent conditions of frailty.

The present study found that an increase of one unit in the AADL score may have a protective effect against occurrences of frailty. These results are corroborated by an investigation among Brazilian elderly people that identified that the chance that frailty would worsen within 12 months was smaller (20\%) when the elderly individual was categorized as "still doing" an AADL. ${ }^{6}$

AADLs are complex activities involving social interaction, such as work or participation in community groups, meetings, cultural events, trips and other activities. ${ }^{15}$ Hence, they represent integrity of physical function, social function and performance in social roles. ${ }^{27}$ In addition, they are predictors of frailty. ${ }^{28}$ Therefore, elderly people with active social networks are likely to be less frail than those with less social engagement. ${ }^{29}$ Moreover, social participation and factors such as security, strong social cohesion and neighborhood belongingness ${ }^{29}$ are protective and provide balance in community frailty levels. ${ }^{30}$

Another frailty predictor is poor physical performance (4-6 points), as assessed using the SPPB. An Italian study with a mean follow-up period of 4.4 years found that poor physical performance (score lower than 8 points) was significantly associated with increased risk of becoming frail and with worsening frailty status. ${ }^{18}$

Previous cross-sectional studies identified the feasibility of using the SPPB to detect frailty among elderly people (score lower than 9 points), ${ }^{31}$ including detection of early signs of frailty before occurrence of slow walking speed among very old people (score

Table 3. Final multinomial logistic regression model including the variables associated with the condition of frailty in a population of communitydwelling elderly people. Uberaba (MG), Brazil, 2014-2016 ( $n=353)$

\begin{tabular}{|c|c|c|c|c|c|c|}
\hline \multirow{3}{*}{ Variables } & \multicolumn{6}{|c|}{ Frailty syndrome } \\
\hline & \multicolumn{3}{|c|}{ Pre-frail } & \multicolumn{3}{|c|}{ Frail } \\
\hline & OR & $95 \% \mathrm{Cl}$ & $\mathbf{P}$ & OR & $95 \% \mathrm{Cl}$ & $\mathbf{P}$ \\
\hline \multicolumn{7}{|c|}{ Age range (in years) } \\
\hline $60-69$ & & 1 & & & 1 & \\
\hline $70-79$ & & - & & & - & \\
\hline 80 or over & 4.92 & $1.57-15.38$ & 0.006 & 8.64 & $2.05-36.35$ & 0.003 \\
\hline \multicolumn{7}{|l|}{ BADL } \\
\hline Dependent & & - & & 3.66 & $1.22-11.02$ & 0.021 \\
\hline Independent & & 1 & & & 1 & \\
\hline AADL & & - & & 0.85 & $0.74-0.99$ & 0.037 \\
\hline \multicolumn{7}{|c|}{$\begin{array}{l}\text { Physical } \\
\text { performance (SPPB) }\end{array}$} \\
\hline Very poor & & - & & & - & \\
\hline Poor & & - & & 7.87 & $1.97-31.39$ & 0.003 \\
\hline Moderate & & - & & & - & \\
\hline Good & & 1 & & & 1 & \\
\hline
\end{tabular}

$\mathrm{OR}=$ odds ratio; $95 \% \mathrm{Cl}=95 \%$ confidence interval; $\mathrm{P}<0.05 ; 1=$ reference category - non-frail group; $B A D L=$ basic activities of daily living; $A A D L=$ advanced activities of daily living; SPPB = Short Physical Performance Battery. of 8 points). ${ }^{32}$ Cesari et al. ${ }^{33,34}$ highlighted that the SPPB identified elderly people with greater vulnerability to stressors and elevated risk of negative health-related events, which are matters related to frailty syndrome. Therefore, these findings may explain the results from the present study.

The SPPB provides a simple measurement of physical performance that is easy to carry out, without any need for special equipment or extensive training for evaluators. ${ }^{32}$ Furthermore, it is one of the clinical tools most used for identifying frailty. ${ }^{35}$ Additionally, it provides a viable and objective definition for the complex concept of frailty, both in clinical practice and in research..$^{33,34}$

Among the limitations of the present study, there were considerable losses of follow-up. A further limitation was that absence of cognitive decline was considered to be an inclusion criterion in the present study, given that presence of cognitive decline could have interfered with comprehension of the variables analyzed (especially considering the self-reported nature of some of the data). Moreover, it needs to be acknowledged that a relationship between frailty and cognitive decline exists.

In the light of the results from the present study and the fact that frailty is a highly prevalent syndrome in aging populations, ${ }^{1}$ it is imperative to identify and manage this condition properly. ${ }^{23}$ In this regard, knowledge of frailty-associated factors and the complexity of their determinants aids construction of early preventive and intervention actions. ${ }^{5,12}$

\section{CONCLUSION}

Being 80 years of age or older was a predictor for conditions of pre-frailty and frailty, while dependency in basic activities of daily living and poor physical performance were predictive of frailty. An increase of one unit in the score for advanced activities of daily living decreased the rate of occurrence of the condition of frailty among these elderly people by $15 \%$.

\section{REFERENCES}

1. Cesari M, Prince M, Thiyagarajan JA, et al. Frailty: An Emerging Public Health Priority. J Am Med Dir Assoc. 2016;17(3):188-92. PMID: 26805753; doi: 10.1016/j.jamda.2015.12.016

2. Morley JE, Vellas B, Van Kan A, Anker SD, Bauer JM, Bernabei R, et al. Frailty consensus: a call to action. J Am Med Dir Assoc. 2013;14(6):39297. PMID: 23764209; doi: 10.1016/j.jamda.2013.03.022.

3. Dent E, Kowal P, Hoogendijk EO. Frailty measurement in research and clinical practice: A review. Eur J Intern Med. 2016;31:3-10. PMID: 27039014; doi: 10.1016/j.ejim.2016.03.007.

4. Feng Z, Lugtenberg M, Franse $C$, et al. Risk factors and protective factors associated with incident or increase of frailty among communitydwelling older adults: A systematic review of longitudinal studies. PLoS One. 2017;12(6):e0178383. PMID: 28617837; doi: 10.1371/journal. pone. 0178383 . 
5. Mello AC, Engstrom EM, Alves LC. Health-related and socio-demographic factors associated with frailty in the elderly: a systematic literature review. Cad. Saúde Pública. 2014;30(6):1 143-68. PMID: 25099040; doi: 10.1590/0102-311X00148213.

6. Alencar MA, Dias JMD, Figueiredo, LC, Dias RC. Transitions in frailty status in community-dwelling older adults. Top Geriatr Rehabil. 2015;31(2):10512. doi: $10.1097 / T G R .0000000000000055$.

7. Marchiori GF, Tavares DMS. Changes in frailty conditions and phenotype components in elderly after hospitalization. Rev LatinoAm Enfermagem. 2017;25:e2905. PMID: 28699992; doi: 10.1590/15188345.1417.2905.

8. Instituto Brasileiro de Geografia e Estatística. Uberaba. 2017. Available from: https://cidades.ibge.gov.br/brasil/mg/uberaba/panorama. Accessed in 2017 (Oct 27).

9. Bertolucci PF, Brucki SMD, Campassi SR, Juliano IO. The Mini-Mental State Examination in an outpatient population: influence of literacy. Arq Neuropsiquiatr. 1994;52(1):1-7. PMID: 8002795; doi: 10.1590/S0004282X1994000100001.

10. Fried LP, Tangen CM, Walston J, et al. Frailty in older adults: evidence for a phenotype. J Gerontol A Biol Sci Med Sci. 2001;56(3):146-56. PMID: 11253156; doi: 10.1093/gerona/56.3.M146.

11. Belisario MS, Dias FA, Pegorari MS, et al. Cross-sectional study on the association between frailty and violence against community-dwelling elderly people in Brazil. Sao Paulo Med J. 2018;136(1):10-9. PMID: 29267538; doi: 10.1590/1516-3180.2017.0203290817.

12. Pegorari MS, Tavares DMS. Factors associated with the frailty syndrome in elderly individuals living in the urban area. Rev Latino-Am Enfermagem. 2014;22(5):874-882. PMID:25493685; doi: 10.1590/0104-1169.0213.2493.

13. Lino VTS, Pereira SRM, Camacho LAB, Ribeiro FST, Buksman S. Crosscultural adaptation of the Independence in Activities of Daily Living Index (Katz Index). Cad Saúde Pública. 2008;24(1):103-12. PMID: 18209838; doi: 10.1590/S0102-311X2008000100010.

14. Santos RL, Virtuoso Júnior JS. Reliability of the Brazilian version of the Scale of Instrumental Activities of Daily Living. Rev Bras Promoção Saúde. 2008;21(4):290-6. doi: 10.5020/575.

15. Ribeiro LHM, Neri AL. Physical exercise, muscle strength and the day-to-day activities of elderly women. Ciênc Saúde Coletiva. 2012;17(8):2169-2180. PMID: 22899157; doi: 10.1590/S141381232012000800027.

16. Camargos FFO, Dias RC, Dias JMD, Freire MTF. Cross-cultural adaptation and evaluation of the psychometric properties of the Falls Efficacy Scale - International Among Elderly Brazilians (FES-I-BRAZIL). Rev Bras Fisioter. 2010;14(3):237-43. PMID: 20730369; doi: 10.1590/S141335552010000300010.

17. Nakano MM. Versão brasileira da Short Physical Performance Battery - SPPB: adaptação cultural e estudo da confiabilidade [dissertation]. Campinas: Universidade Estadual de Campinas; 2007. Available from: http://repositorio.unicamp.br/jspui/handle/REPOSIP/252485. Accessed in 2019 (Oct 14).
18. Trevisan C, Veronese N, Maggi S, et al. Factors Influencing Transitions Between Frailty States in Elderly Adults: The Progetto Veneto Anziani Longitudinal Study. J Am Geriatr Soc. 2017;65(1):179-84. PMID: 27861714; doi: 10.1111/jgs.14515.

19. Harttgen K, Kowal P, Strulik H, Chatterji S, Vollmer S. Patterns of frailty in older adults: comparing results from higher and lower income countries using the Survey of Health, Ageing and Retirement in Europe (SHARE) and the Study on Global AGEing and Adult Health (SAGE). PLoS One. 2013;8(10):e75847. PMID: 24204581; doi: 10.1371/journal. pone.0075847.

20. Lee JSW, Auyeung TW, Leung J, KwokT, Woo J. Transitions in frailty states among community-living older adults and their associated factors. $J$ Am Med Dir Assoc. 2014;15(4):281-86. PMID: 24534517; doi: 10.1016/j. jamda.2013.12.002.

21. Chang SF, Lin PL. Frail phenotype and mortality prediction: a systematic review and meta-analysis of prospective cohort studies. Int J Nurs Stud. 2015;52(8):1362-74. PMID: 25986959; doi: 10.1016/j.jjnurstu.2015.04.005.

22. Fulop T, Larbi A, Witkowski JM, et al. Aging, frailty and age-related diseases. Biogerontology. 2010;11(5):547-63. PMID: 20559726; doi: 10.1007/s10522-010-9287-2.

23. Dent E, Lien C, Lim WS, et al. The Asia-Pacific Clinical Practice Guidelines for the Management of Frailty. J Am Med Dir Assoc. 2017;18(7):564-75. PMID: 28648901; doi: 10.1016/j.jamda.2017.04.018.

24. Fried LP, Ferrucci L, Darer J, Williamson JD, Anderson G. Untangling the concepts of disability, frailty, and comorbidity: implications for improved targeting and care. J Gerontol A Biol Sci Med Sci. 2004;59(3):255-63. PMID: 15031310; doi: 10.1093/gerona/59.3.m255.

25. Vieira RA, Guerra RO, Giacomin KC, et al. Prevalence of frailty and associated factors in community-dwelling elderly in Belo Horizonte, Minas Gerais State, Brazil: data from the FIBRA study. Cad Saúde Pública. 2013;29(8):1631-43. PMID: 24005928; doi: 10.1590/0102$311 \times 00126312$.

26. Tavares DMS, Pelizaro PB, Pegorari MS, Paiva MM, Marchiori GF. Functional disability and associated factors in urban elderly: a population-based study. Rev Bras Cineantropom Desempenho Hum. 2016;18(5):499-508. doi: 10.5007/1980-0037.2016v18n5p499.

27. Dias EG, Andrade FB, Duarte YAO, Santos JLF, Lebrão ML. Advanced activities of daily living and incidence of cognitive decline in the elderly: the SABE Study. Cad. Saúde Pública. 2015;31(8):1623-35. PMID: 26375642; doi: 10.1590/0102-311X00125014.

28. Woo J, Goggins W, Sham A, Ho SC. Social determinants of frailty. Gerontology. 2005;51(6):402-8. PMID: 16299422; doi: 10.1159/000088705.

29. Cramm JM, Nieboer AP. Relationships between frailty, neighborhood security, social cohesion and sense of belonging among communitydwelling older people. Geriatr Gerontol Int. 2013;13(3):759-63. PMID: 23190426; doi: 10.1111/j.1447-0594.2012.00967.

30. Duppen D, Van der Elst MC, Dury S, et al. The Social Environment's Relationship With Frailty. J Appl Gerontol. 2017 Jan 1:733464816688310. PMID: 28380715; doi: 10.1177/0733464816688310. 
31. Da Câmara SM, Alvarado BE, Guralnik JM, Guerra RO, Maciel AC. Using the Short Physical Performance Battery to screen for frailty in youngold adults with distinct socioeconomic conditions. Geriatr Gerontol Int. 2013;13(2):421-8. PMID: 22882512; doi: 10.1111/j.1447-0594.2012.00920.x.

32. Verghese J, Xue $X$. Identifying frailty in high functioning older adults with normal mobility. Age Ageing. 2010; 39(3):382-85. PMID: 20051607; doi: 10.1093/ageing/afp226.

33. Cesari M, Marzetti E, Calvani R, et al. The need of operational paradigms for frailty in older persons: the SPRINTT project. Aging Clin Exp Res. 2017;29(1):3-10. PMID: 28155179; doi: 10.1007/s40520-016-0712-5.

34. Cesari M, Landi F, Calvani R, et al. Rationale for a preliminary operational definition of physical frailty and sarcopenia in the SPRINTT trial. Aging Clin Exp Res. 2017;29(1):81-8. PMID:28188558; doi: 10.1007/s40520-016-0716-1.

35. Bruyère $O$, Buckinx $F$, Beaudart $C$, et al. How clinical practitioners assess frailty in their daily practice: an international survey. Aging Clin Exp Res. 2017;29(5):905-12. PMID: 28770478; doi: 10.1007/s40520-017-0806-8.

This study was presented at the XXI Congresso Brasileiro de Geriatria e Gerontologia, in Rio de Janeiro, RJ, Brazil, in 2018

Sources of funding: Fundação de Amparo à Pesquisa de Minas Gerais (FAPEMIG; APQ 02035-14) and Conselho Nacional de Desenvolvimento Científico e Tecnológico (CNPq; 305617/2015-0)

Conflict of interest: None

Date of first submission: May 14, 2019

Last received: July 11, 2019

Accepted: September 19, 2019

\section{Address for correspondence:}

Darlene Mara dos Santos Tavares

Departamento de Enfermagem em Educação e Saúde Comunitária

do Curso de Graduação em Enfermagem da Universidade Federal do

Triangulo Mineiro (UFTM)

Av. Frei Paulino, 30

Abadia — Uberaba (MG) - Brasil

CEP 38025-180

Tel. (+55 34) 3700-6154

E-mail: darlene.tavares@uftm.edu.br 